\title{
Effect of Different Housing System on the Performance, Bone Mineral Density and Yolk Fatty Acid Composition in Laying Hen
}

\author{
Md. Rakibul Hassan ${ }^{1}$, Shabiha Sultana ${ }^{1}$, Ho Sung Choe ${ }^{2}$ and Kyeong Seon Ryu ${ }^{1,+}$ \\ ${ }^{I}$ Department of Animal Science, Chonbuk National University, Jeonju 561-756, Republic of Korea \\ ${ }^{2}$ Department of Animal Biotechnology, Chonbuk National University, Jeonju 561-756, Republic of Korea
}

\begin{abstract}
Different housing systems have considerable influence on performance in poultry production. Therefore, the present study was undertaken to investigate the impact of different housing systems on the performance, bone mineral density and egg yolk fatty acid composition in laying hen. Hy-line brown pullets $(\mathrm{n}=450)$ of 12 weeks age were randomly divided into 3 housing systems with 6 replicates of 25 birds in each room. A diet with 2,750 kcal $/ \mathrm{kg} \mathrm{ME}$ and $16.5 \%$ CP was assigned to all birds. The pullets provided free access to feed and water. Significantly $(P<0.05)$ higher values for egg production, egg mass and feed conversion efficiency were found in battery cages, however egg weight, egg shell color and breaking strength was remarkably $(P<0.05)$ higher in floor system. The albumin height and Haugh unit were significantly higher $(P<0.05)$ in battery cages which was statistically similar to aviary housing system. The egg yolk fatty acids concentration of linoleic acid and linolenic acids were significantly higher in aviary and in floor system, respectively, however both values were lower in battery cages. Saturated and unsaturated fatty acid content (\%) in egg yolk did not influence by any housing systems. Bone mineral density was significantly higher $(P<0.05)$ in floor and aviary housing system than that of battery cage system. It was concluded that in battery cages the egg production and composition maximized, however higher bone mineral density and yolk fatty acids content can be improved in the laying hen reared on floor and aviary housing systems.
\end{abstract}

(Key words : housing system, performance, bone mineral density and fatty acid composition)

\section{INTRODUCTION}

Battery cage is a worldwide housing system in modern egg production which constitutes approximately $90 \%$ of all laying hens' commercial production. But, in the past few years' battery cages has been criticized around the world especially in European Union. From 2012, European Union not allowing battery cage housing system. Therefore, there is a need to find out the suitable alternative of battery cage for better production performance of the bird. Several alternative housing systems such as floor litter, perchery, aviary, free range and enriched cage system have been proposed and increasingly practiced since past two decades. Aviaries housing systems may be the possible alternative to cages and provides more comfortable environment for birds. However, the effects of housing systems on the performance are conflicting and inconclusive. Taylor and Hurnik (1996) and Süto et al. (1997) mentioned that, different housing systems have considerable effects on perfor- mance (egg weight, feed efficiency, daily feed consumption, and mortality). Yousaf and Ahmad (2006) and Thomas and Ravindran (2005) found that caged bird produced more number of eggs against floor and barn system. When conventional cage and aviary production were compared, no differences were detected in internal egg quality (Abrahamsson and Tauson, 1995). On the other hand, Cherian et al. (2002) compared the fatty acid composition of egg yolk and found no clear influence of housing system on lipid composition. However a clear influence of housing system is not yet established. Most of the research on the effects of housing systems on the performance and lipid composition of laying hens has been investigated in other countries, but in this aspect there is a scarcity of literature in the Republic of Korea. Thus, the objective of the present study was to determine the influence of housing system applied from 12 to 56 wks of age on performance, bone mineral density and yolk lipid composition of Hy-Line brown hens.

\footnotetext{
${ }^{\dagger}$ To whom correspondence should be addressed : seon@jbnu.ac.kr
} 


\section{MATERIALS AND METHODS}

\section{Feeding Trial and Management}

At 12 weeks of age, Hy-Line brown pullets $(n=450)$ were purchased from a commercial farm. Upon arrival, pullets were randomly divided into 3 groups to be reared in three housing systems, which were (1) litter floor, (2) aviary and (3) battery cage. Each housing system had 6 replications with 25 birds in each room. All the birds were assigned to a standard layer diet with $2,750 \mathrm{kcal} / \mathrm{kg} \mathrm{ME}$ and $16.5 \% \mathrm{CP}$ and were fed $\mathrm{ad}$ libitum. Ingredients and nutrient composition of experimental diets were shown in Table 1 . The light schedule was $10 \mathrm{~h}$ light and $14 \mathrm{~h}$ dark from 12 wks of age and increased in stepwise manner per week and reached $16 \mathrm{~h}$ on 18 wks of age. In floor rearing system, 25 hens were housed per floor pen (360 $\mathrm{cm}$ length and $170 \mathrm{~cm}$ width). The floor was equipped with long feeder $(200 \mathrm{~cm})$, nipple drinker, perches and laying nest $(160 \mathrm{~cm})$. In battery cages, a total of 150 hens, occupying floor space of about $450 \mathrm{~cm}^{2}$ per hen, were housed in 3 tier cage system containing 75 cage boxes $(36 \mathrm{~cm} \times 24 \mathrm{~cm} \times 40$ $\mathrm{cm})$. In aviary housing system, 25 hens were allotted per pen (220 cm length, $190 \mathrm{~cm}$ width and $260 \mathrm{~cm}$ height). Each pen was equipped with over $200 \mathrm{~cm}$ long feeder with nipple drinker, nest (120 cm long) and perches (190 cm length). The floor of the house served as a scratching area and was furnished with a small layer of rice husk. To prevent any preferences for familiar odors interfering with the housing system, each pen were cleaned daily. Fresh water and feed were provided and eggs were collected daily in the afternoon. A ventilation fan in the roof of the central arena was fitted which circulated fresh air inside the pen. Air temperature $\left(17 \sim 21^{\circ} \mathrm{C}\right)$ and humidity were measured inside each pen to ensure that any preferences/deference in each pen occurring was due to housing not due the temperature or humidity.

\section{Laying Performance and Egg Quality}

During the growing period, body weights were measured at $13^{\text {th }}$ to $20^{\text {th }}$ weeks of age and in laying period, egg production, egg weight and feed consumption per group were recorded daily. Egg mass (\% of egg production $\times$ egg weight/ 100 ) and feed conversion ( $\mathrm{g}$ of feed/g of egg) were calculated based on the egg production, egg weight and feed con-
Table 1. Experimental diet composition

\begin{tabular}{|c|c|}
\hline Ingredients & Concentration \\
\hline Corn & 53.598 \\
\hline Soybean meal & 15.780 \\
\hline Wheat & 6.000 \\
\hline Wheat bran & 6.000 \\
\hline Canola meal & 3.000 \\
\hline Corn gluten meal & 3.414 \\
\hline Tallow & 1.500 \\
\hline Lime stone & 9.125 \\
\hline DCP & 0.910 \\
\hline Salt & 0.361 \\
\hline L-Lysine (78\%) & 0.068 \\
\hline DL-Methionine (99\%) & 0.046 \\
\hline Vitamin $_{\text {premix }}{ }^{1}$ & 0.100 \\
\hline Mineral premix ${ }^{2}$ & 0.100 \\
\hline Total & 100 \\
\hline \multicolumn{2}{|l|}{ Composition } \\
\hline $\mathrm{ME}(\mathrm{kcal} / \mathrm{kg})$ & 2,750 \\
\hline CP (\%) & 16.5 \\
\hline Lysine (\%) & 0.784 \\
\hline Methionine (\%) & 0.340 \\
\hline $\mathrm{Ca}(\%)$ & 3.750 \\
\hline Available phosphate (\%) & 0.275 \\
\hline Sodium & 0.165 \\
\hline
\end{tabular}

${ }^{1}$ Contain per kg: retinol, $3.6 \mathrm{mg}$; cholecalciferol, $0.125 \mathrm{mg}$; tocopherol, $50 \mathrm{mg}$; menadione, $3 \mathrm{mg}$; thiamine, $2 \mathrm{mg}$; riboflavin, $6 \mathrm{mg}$; pyridoxine, $4 \mathrm{mg}$; cyanocobalamin, $0.025 \mathrm{mg}$; biotin, $0.15 \mathrm{mg}$; pantothenic acid, $20 \mathrm{mg}$; folic acid, $2 \mathrm{mg}$; nicotinic acid, $7 \mathrm{mg}$.

${ }^{2}$ Contain per kg; Fe, 66.720 mg; Cu, 41.70 mg; Mn, 83.40 mg; $\mathrm{Zn}, 66.72 \mathrm{mg}$; I, $0.834 \mathrm{mg}$; Se, $0.25 \mathrm{mg}$.

sumption. At the end of experiment (56 weeks), 30 eggs from each treatment were selected randomly to measure egg components. Egg shell breaking strength was determined by egg multi-tester instrument (QC-SPA, TSS, UK). The eggs were weighed individually and broken on a glass plate to study egg quality parameters (shell color, albumin height, Haugh units 
and yolk color) which were measured by using egg quality equipment (QCM+-System, TSS, UK).

\section{Measurement of Bone Mineral Density}

At 56 weeks of age, 10 hens from each housing system with similar body weight $(1,950 \pm 50 \mathrm{~g})$ were selected and killed by cervical dislocation. Tibia was removed from the muscles to measured bone mineral densities (BMD) by using Bone Densitometer (pDEXA, Norland Medical Systems Inc., USA).

\section{Measurement of Fatty Acid}

For fatty acid estimation, one $g$ of fresh egg yolk was precisely weighed in glass tubes and dissolved in $4 \mathrm{~mL}$ of methanol-benzene $(4: 1, \mathrm{v} / \mathrm{v})$. Thereafter, $200 \mu \mathrm{L}$ of acetyl chloride was slowly added over a period of $1 \mathrm{~min}$ and tubes were tightly closed with Teflon-lined caps and subjected to methanolysis at $100^{\circ} \mathrm{C}$ for $1 \mathrm{hr}$. After providing a cooling period of $15 \mathrm{~min}$ at room temperature, $2 \mathrm{~mL}$ of $6 \% \mathrm{~K}_{2} \mathrm{CO}_{3}$ was added in the tubes followed by the addition of $2 \mathrm{~mL}$ hexane for vortexed. The tubes were then shaken and centrifuged at 1,700 $\mathrm{g}$ for $20 \mathrm{~min}$. An aliquot of the upper phase hexane was injected into the chromatograph. Fatty acids were chromatographed as methyl esters on a 30-m fused silica column having an internal diameter of $0.25 \mu \mathrm{m}$. The column was wallcoated with $0.20 \mathrm{~mm}$ Supelco ${ }^{\mathrm{TM}} 10$. Analysis was performed on an Agilent Technologies $6890 \mathrm{~N}$, gas chromatograph, equipped with a flame ionization detector. Helium was used as carrier gas and nitrogen as make-up gas. The split ratio was 100:1. The injection port temperature in oven condition and the detector was $240^{\circ} \mathrm{C}$. The column temperature raised in a stepwise manner from $180^{\circ} \mathrm{C}$ up to $230^{\circ} \mathrm{C}$ at the rate of $3^{\circ} \mathrm{C} / \mathrm{min}$ and then holds for $15 \mathrm{~min}$. The gas chromatograph was calibrated using a standard mixture of fatty acid.

\section{Statistical Analysis}

All the collected data were analyzed using analysis of variance on the GLM program of SAS (Version 9.1, Cary, NC, 2005). The post-hoc tests were performed using Duncan's multiple range tests (Steel and Torrie, 1980) and the statistical significance between the treatment intervals was determined at the $5 \%$ level.

\section{RESULTS}

\section{Egg Production, Feed Intake and Feed Con- version Ratio}

The performance of laying hens was significantly influenced due to housing systems (Table 2). Values for egg production and egg mass obtained from the birds reared in battery cages were significantly higher than that of floor and aviary housing systems. On the other hand, egg weight was higher in floor rearing systems. Higher feed intake and better FCR were attained from the floor and battery cage systems, respectively, however the values for FCR in floor and aviary was statistically similar. A consistently higher egg production (18 56 weeks of age) was observed in battery cage system than those of floor and aviary housing system (Fig. 2). From 18 26 weeks of age, higher egg production was obtained from aviary housing system which was later on decrease due to higher egg production in floor housing system. During the growing period (13 $\sim 20$ weeks), body weight was significantly influenced by the housing system where higher weight gain was observed at floor system and lower in aviary system. (Fig. 1).

\section{Bone Mineral Density of Laying Hen}

Bone mineral density (BMD) was significantly higher $(P<$ $0.05)$ in floor $\left(0.258 \mathrm{~g} / \mathrm{cm}^{2}\right)$ and aviary $\left(0.244 \mathrm{~g} / \mathrm{cm}^{2}\right)$ housing system than that of battery cage $\left(0.225 \mathrm{~g} / \mathrm{cm}^{2}\right)$ rearing system (Fig. 3). However, the values were not statistically significant between floor and aviary.

Table 2. Effects of three housing system on the performance in laying hens

\begin{tabular}{lccc}
\hline \multirow{2}{*}{ Parameters } & \multicolumn{3}{c}{ Housing systems } \\
\cline { 2 - 4 } & Battery cage & Aviary & Floor \\
\hline Egg production (\%) & $88.83 \pm 0.67^{\mathrm{a}}$ & $82.27 \pm 0.92^{\mathrm{c}}$ & $85.77 \pm 1.23^{\mathrm{b}}$ \\
Egg weight (g) & $63.98 \pm 0.33^{\mathrm{b}}$ & $62.20 \pm 0.34^{\mathrm{b}}$ & $65.18 \pm 0.19^{\mathrm{a}}$ \\
Egg mass & $56.83 \pm 0.48^{\mathrm{a}}$ & $51.17 \pm 0.57^{\mathrm{c}}$ & $53.95 \pm 0.80^{\mathrm{b}}$ \\
Feed intake (g) & $131.19 \pm 1.37^{\mathrm{b}}$ & $131.99 \pm 1.66^{\mathrm{b}}$ & $135.21 \pm 2.48^{\mathrm{a}}$ \\
Feed conversion & $2.380 \pm 0.03^{\mathrm{b}}$ & $2.573 \pm 0.04^{\mathrm{a}}$ & $2.506 \pm 0.04^{\mathrm{a}}$ \\
\hline
\end{tabular}

a,b Value with the same letters in the row are not significantly different at $5 \%$ level. 


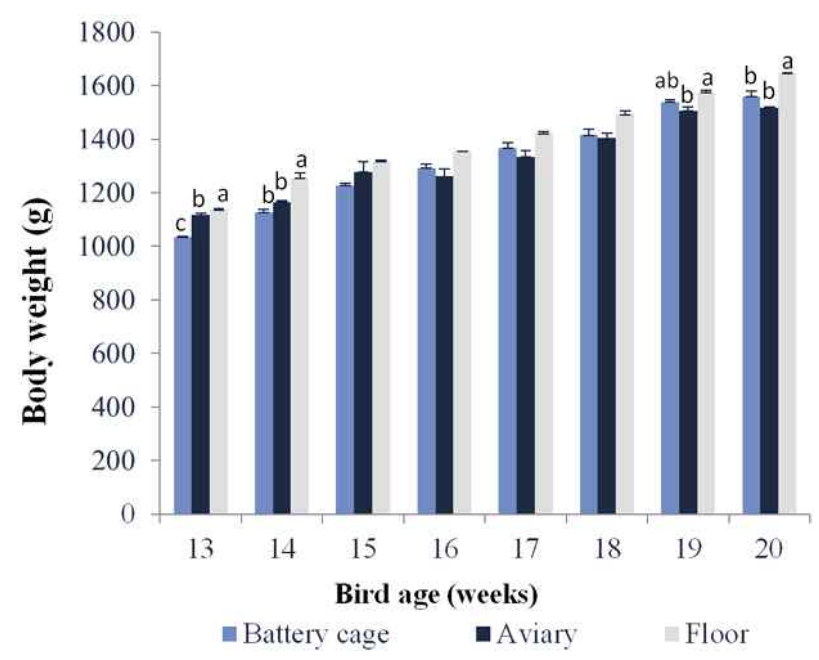

Fig. 1. Effect of different housing system on body weight of hy-line brown pullet.

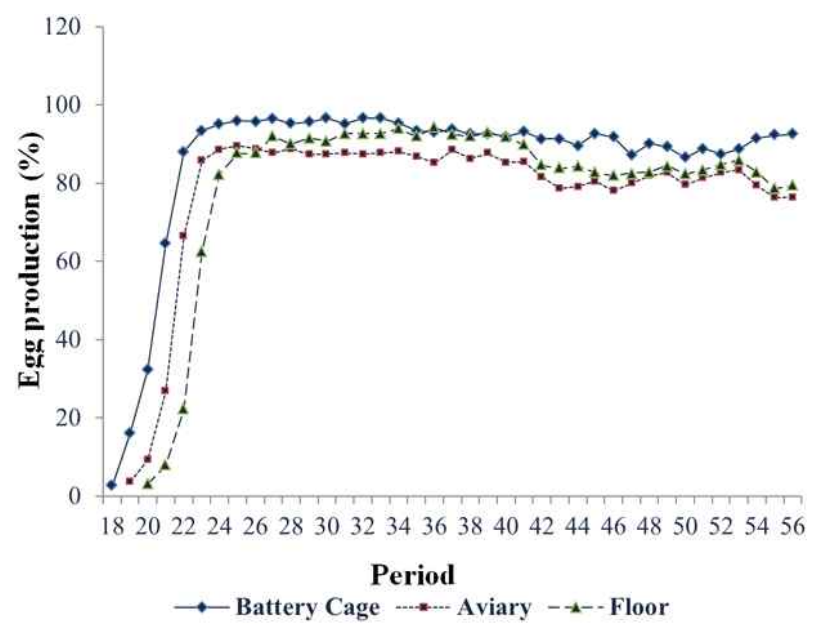

Fig. 2. Effect of different housing system on egg production of laying hen.

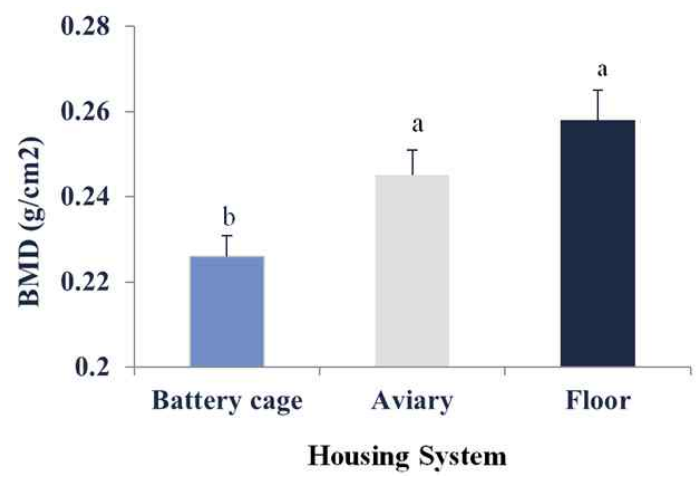

Fig. 3. Effect of different housing system on bone mineral density of hy-line brown hen.

\section{Egg Quality in Laying Hens}

Egg shell color was significantly $(P<0.05)$ higher in floor system; however it was lower in battery and aviary housing system, respectively (Table 3 ). Values for egg yolk was significantly $(P<0.05)$ higher at aviary system which was statistically similar to floor housing system. In contrast, egg shell breaking strength was highly affected $(P<0.05)$ at floor system, however the values were statistically similar to battery cage housing system. Significantly higher $(P<0.05)$ values for albumin height and Haugh unit were obtained at battery cages which were statistically similar to aviary housing system. However, for these parameters floor housing system was not found so effective compared to battery and aviary housing system.

\section{Fatty Acid Composition in Egg Yolk}

Mean relative fatty acid composition for each housing system is presented in Table 4. Oleic $\left(\mathrm{C}_{18: \ln 9}, 35 \sim 37 \%\right)$, palmitic $\left(\mathrm{C}_{16: 0}, 26 \sim 28 \%\right)$, stearic acid $\left(\mathrm{C}_{18: 0}, 14 \sim 15 \%\right)$ and linoleic $\left(\mathrm{C}_{18: 2 \mathrm{n} 6}, 11 \sim 14 \%\right)$ acids are the major fatty acids in egg yolk. Among the yolk fatty acid, a significantly higher value $(P<$ 0.05 ) for linoleic acid was recorded in aviary system however in floor system the values for linolenic acid were higher. The concentration for both the parameters was found to be lower in battery cages. In the present experiment, saturated fatty acids (SFA), unsaturated fatty acids (UFA) and SFA:UFA ratio was not varied by the housing systems. In the egg yolk, saturated (myristic $\mathrm{C}_{14: 0}$, palmitic $\mathrm{C}_{16: 0}$, stearic $\mathrm{C}_{18: 0}$ ) and unsa-

Table 3. Effects of three housing system on the egg quality in laying hens at the 56 weeks

\begin{tabular}{lccc}
\hline \multirow{2}{*}{ Parameters } & \multicolumn{3}{c}{ Housing systems } \\
\cline { 2 - 4 } & Battery cage & Aviary & Floor \\
\hline Egg shell color & $25.80 \pm 0.44^{\mathrm{b}}$ & $23.83 \pm 0.31^{\mathrm{c}}$ & $27.10 \pm 0.40^{\mathrm{a}}$ \\
Albumin height (mm) & $9.49 \pm 0.10^{\mathrm{a}}$ & $9.31 \pm 0.19^{\mathrm{a}}$ & $8.71 \pm 0.11^{\mathrm{b}}$ \\
Haugh unit & $91.77 \pm 0.53^{\mathrm{a}}$ & $90.89 \pm 0.64^{\mathrm{a}}$ & $87.10 \pm 1.56^{\mathrm{b}}$ \\
Yolk color & $6.71 \pm 0.01^{\mathrm{b}}$ & $6.96 \pm 0.07^{\mathrm{ab}}$ & $6.94 \pm 0.06^{\mathrm{a}}$ \\
Egg shell breaking & $4.56 \pm 0.09^{\mathrm{ab}}$ & $4.42 \pm 0.07^{\mathrm{b}}$ & $4.71 \pm 0.08^{\mathrm{a}}$ \\
strength $\left(\mathrm{kg} / \mathrm{cm}^{2}\right)$ & & & \\
\hline
\end{tabular}

${ }^{\mathrm{a}, \mathrm{b}}$ Value with the same letters in the row are not significantly different at $5 \%$ level. 
Table 4. Effects of three housing system on the egg yolk fatty acid in laying hens

\begin{tabular}{lccc}
\hline \hline \multirow{2}{*}{ Parameters } & \multicolumn{3}{c}{ Housing systems } \\
\cline { 2 - 4 } & Battery cage & Aviary & Floor \\
\hline $\mathrm{C}_{14: 0}$ & $0.28 \pm 0.01$ & $0.27 \pm 0.01$ & $0.27 \pm 0.01$ \\
$\mathrm{C}_{16: 0}$ & $27.31 \pm 0.22$ & $27.09 \pm 0.17$ & $26.93 \pm 0.18$ \\
$\mathrm{C}_{16: \ln 7}$ & $2.77 \pm 0.09$ & $2.42 \pm 0.14$ & $2.56 \pm 0.10$ \\
$\mathrm{C}_{18: 0}$ & $14.58 \pm 0.21$ & $14.76 \pm 0.18$ & $15.02 \pm 0.17$ \\
$\mathrm{C}_{18: \ln 9}$ & $36.63 \pm 0.42$ & $35.98 \pm 0.41$ & $36.76 \pm 0.31$ \\
$\mathrm{C}_{18: 2 n 6}$ & $12.41 \pm 0.35^{\mathrm{b}}$ & $13.57 \pm 0.36^{\mathrm{a}}$ & $11.74 \pm 0.31^{\mathrm{b}}$ \\
$\mathrm{C}_{18: 3 n 3}$ & $0.77 \pm 0.14^{\mathrm{b}}$ & $0.64 \pm 0.14^{\mathrm{b}}$ & $1.21 \pm 0.11^{\mathrm{a}}$ \\
$\mathrm{C}_{20: 4 n 6}$ & $5.27 \pm 0.10$ & $5.29 \pm 0.07$ & $5.47 \pm 0.08$ \\
\hline \multicolumn{1}{c}{ SFA $^{1}$} & $42.18 \pm 0.19$ & $42.14 \pm 0.17$ & $42.23 \pm 0.09$ \\
\multicolumn{1}{c}{ UFA $^{2}$} & $57.81 \pm 0.19$ & $57.67 \pm 0.17$ & $57.76 \pm 0.09$ \\
\multicolumn{1}{c}{ UFA/SFA } & $1.37 \pm 0.01$ & $1.37 \pm 0.01$ & $1.37 \pm 0.01$ \\
\hline
\end{tabular}

${ }^{\mathrm{a}, \mathrm{b}}$ Value \pm standard error with the same letters in the row are not significantly different at 5\% level.

${ }^{1}$ Saturated fatty acid.

${ }^{2}$ Unsaturated fatty acid. SFA=Saturated fatty acids were calculated as $\mathrm{C}_{14: 0}+\mathrm{C}_{16: 0}+\mathrm{C}_{18: 0}$; UFA=Unsaturated fatty acids were calculated as $\mathrm{C}_{16: \ln 7}+\mathrm{C}_{18: \ln 9}+\mathrm{C}_{18: 2 \mathrm{n} 6}+\mathrm{C}_{18: 3 \mathrm{n} 3}+\mathrm{C}_{20: 4 n 6}$

turated fatty acid (palmitolic $\mathrm{C}_{16: \ln 7}$, oleic $\mathrm{C}_{18: \ln 9}$ and arachidonic acid $\mathrm{C}_{20: 4 n 6}$ ) remained un-influenced by the housing system.

\section{DISCUSSION}

In the present study, performances of laying hens were significantly influenced among the aviary, floor and battery cage hosing system. Egg production and egg mass were significantly higher in battery cages than that of aviaries. The present finding is in line with Yousaf and Ahmad (2006) and Thomas and Ravindran (2005), who found that the birds kept in battery cage, produced more number of eggs against floor litter and barn system. However, in the previous experiment, Etches (1996) did not found any difference either in egg production or in egg weight in laying hens. On the other hand, egg weight was remarkably higher in floor rearing system which corresponds with the findings of Yousaf and Ahmad (2006) and
Vits et al. (2005) who also found greater egg weights in floor pens than in battery cages. This might be due to the body size in the growing period (13 20 weeks), birds kept on the floor were heavier than those of aviary and caged birds. Heavier birds in the floor pens could be attributed to better physical condition and those birds laid larger eggs because body weight and egg weights are positively correlated (Siegel, 1962). In contrast, Yakabu et al. (2007) found that eggs from conventional cages were larger than those of the floor pens. Several researchers (Thomas and Ravindran, 2005; Van Den Brank et al., 2004; Taylor and Hurnik, 1996; Torges et al., 1976; Mostert et al., 1995) mentioned that egg weight was not affected by the housing system. In present experiment feed intake was significantly higher in floor rearing system and better FCR was attained in the battery cage rearing system. The reason might be due to their increased motor activities in the floor and aviary housing system and which increased the maintenance requirement. This finding corresponds with the findings of Yousaf and Ahmad (2006). Taylor and Hurnik (1996) examined the long-term effects of housing system and found that feed consumption and conversion tended to be higher in the aviary than that of battery cage system. On the other hand, Van Horne (1996) found that poorer feed conversion in aviary system and which is similar with the present findings. In another experiment, Thomas and Ravindran (2005) mentioned that housing systems did not influence either feed intake or feed conversion efficiency of laying hen.

In the present study, marked differences in egg quality were observed due to the aviary, floor and battery cage hosing system. Albumen height was significantly lower in floor pens than that in battery cages and aviary system which might be due to the exposure to ammonia from litter that may affects albumen quality. The present results correspond with the findings of Roberts (2004) and Süto et al. (1997). Convertsely, egg shell color and shell breaking strength was significantly higher in floor system than that of aviary and battery cage rearing system. The reason might be due to increased activity in the floor system and which may beneficial for calcium metabolism. In a previous study, Leyendecker et al. (2005) reported thicker shells in free range eggs than that of conventional cage and aviary systems. In contrast, Roberts et al. (1995) and Tumova and Ebeid (2003) mentioned that caged eggs 
showed beneficial ultrastructural features which contribute eggshell strength. Casiraghi et al. (2005) mentioned that egg weight is correlated with shell breaking strength. On the other hand, Van den Brand et al. (2004) did not find differences between free range and battery cage. Birds in battery cages showed higher Haugh unit compared to floor system but have no difference with the aviary rearing system which agreed the findings of Yousaf and Ahmad (2006). Deeper yolk color was found from floor systems than that of battery cage system. Similar results were also found by Süto et al. (1997) and Pištěková et al. (2006) with greater yolk color in floor pens than in cages, however, no potential reason for the difference was provided. Van Den Brand et al. (2004) reported a clear effect of outdoor housing system on yolk color and a darker yolk. Karunajeewa (1978) reported that the yolk color mainly determined by the xanthophylls.

Bone mineral density (BMD) was significantly higher $(p<$ 0.05 ) in floor and aviary housing system than that of battery cage rearing system due to the increased opportunity to exercise. In a study conducted by Whitehead (2000) bone mineral volume was reduced when the hens were kept in conventional cages with higher egg production due to immobilization of hens in cages. Another factor that may have contributed to lower bone degeneration in the aviary system is that the hens in the aviary laid eggs of lower weight.

Linoleic acid and linolenic acid were significantly higher in aviary and floor system, respectively. The reason might be hens consume more feeds and allow more of the dietary fatty acids to be secreted in the eggs. However, in the previous results, Watkins (1995) mentioned highest concentration of monounsatured fatty acid in litter floor and linoleic and linolenic acid in battery cages. On the other hand, saturated and unsaturated fatty acid content in egg yolk was not influenced by the housing system which is similar with the results of Cherian et al. (2002). Cerolini et al. (2005) observed that housing system did not influence the cholesterol concentration of eggs. Moreover, several workers mentioned that, egg yolk fatty acid component is mainly affected by feeding programmes (Milinsk et al., 2003), dietary lipids, genetics and age (Cobos et al., 1995, Hidalgo et al., 2008). However, no differences in fatty acid composition among battery cage, free-range, floor or organic labeled eggs were observed.

\section{CONCLUSIONS}

It was concluded that egg production and egg mass were enhanced in battery cages and egg weight in floor rearing system. Bone mineral density was significantly higher in floor and aviary housing system. Egg yolk color, egg shell color and shell breaking strength were improved in floor rearing system, however; the values for albumin height and Haugh unit were higher in battery cages. The higher concentration of fatty acid and linoleic acid in egg yolk was observed in aviary but linolenic acid was higher in floor system. Thus, the egg production and composition were maximized in battery cages and higher bone mineral density and yolk fatty acids content can be obtained from the laying hens reared in floor and aviary housing systems.

\section{LITERATURE CITED}

Abrahamsson P, Tauson R 1995 Aviary systems and conventional cages for laying hens: effects on production, egg quality, health and bird location in three hybrids. Acta Agriculturae Scandinavica, Section A. Anim Sci 45:191-203.

Casiraghi E, Hidalgo A, Rossi M 2005 Influence of weight grade on shell characteristics of marketed hen eggs. In Proceedings of the XI European Symposium on the Quality of Eggs and Egg Products, Doorwerth, The Netherlands: 183-188.

Cerolini S, Zaniboni L, Cognata LR 2005 Lipid characteristics in eggs produced in different housing systems. Italian $\mathrm{J}$ Anim Sci 4:520.

Cherian G, Holsonbake TB, Goeger MP 2002 Fatty acid composition and egg components of speciality eggs. Poultry Sci 81:30-33.

Cobos, A, De La Hoz L, Cambero MI, Ordóñez JA 1995 Dietary modification and hen strain dependence of egg yolk lipids. Food Res Int 28:71-76.

Etches RJ 1996 Egg formation, in: Reprod in Poult pp. 167-207 (Wallingford, CAB Int). ISBN 0-85198-738-9.

Hidalgo A, Rossi M, Clerici F, Ratti S 2008 A market study on the quality characteristics of eggs from different housing systems. Food Chem 106:1031-1038.

Karunajeewa H 1978 The performance of Cross-bred hens 
given free choice feeding of whole grains and a concentrate mixture and the influence of source of xantophylls on yolk colour. Br Poult Sci 19:699.

Leyendecker M, Hamann H, Hartung J, Kamphues J, Neumann U, Surie C, Distl O 2005 Keeping laying hens in furnished cages and an aviary housing system enhances their bone stability. Br Poult Sci 46:536-544.

Milinsk MC, Murakami AE, Gomes STM, Matsushita M, De Souza, NE 2003 Fatty acid profile of egg yolk lipids from hens fed diets rich in n-3 fatty acids. Food Chem 83:287292.

Mostert BE, Bowers EH, Van Der Walt JC 1995 Influence of different housing systems on the performance of hens of four laying strains. South African J Anim Sci 25:80-86.

Pištěková V, Hovorka M, Večerek V, Straková E, Suchý P 2006 The quality comparison of eggs laid by laying hens kept in battery cages and in a deep litter system. Czech J Anim Sci 51:318-325.

Roberts JR 2004 Factors affecting egg internal quality and egg shell quality in laying hens. J Poult Sci 41:161-177.

Roberts JR, Brackpol CE, Solomon SE 1995 The ultrastructure of good and poor quality eggshells from Australian layer strains. Proceedings of the VI European Symposium on the Quality of Eggs and Egg Products. Spain:107-115.

SAS 2005 SAS User's Guide. Statistical Analysis System Institute. Ver. 9.1 ed Inc., Carry NC.

Siegel PB 1962 Selection for body weight at eight weeks of age. Short term response and heritabilities. Poultry Sci 41: 954-962.

Steel RGD, Torrie JH 1980 Analysis of Covariance. Principles and Procedures of Statistics: A Biometrical Approach. McGraw-Hill, New York. pp. 401-437.

Süto, Z, Horn P, Ujvári J 1997 The effect of different housing systems on production and egg quality traits of brown and Leghorn type layers. Acta Agraria Kaposváriensis 1:29-35.

Taylor AA, Hurnik JF 1996 The long-term productivity of hens housed in battery cages and an aviary. Poultry Sci 75:4751.

Thomas DV, Ravindran V 2005 Comparison of layer performance in cage and barn systems. J Anim Vet Adv 4:554-556.

Torges H, Matthes G, Harnish S 1976 Comparative studies of the quality of eggs obtained from farms using free range floor and cage systems of hen rearing. Archiv Fur Lebensmittelhygiene 27:107-112.

Tumova E, Ebeid T 2003 Effect of housing system on performance and egg quality characteristics in laying hens. Scientia Agriculturae Bohemica 34:73-80.

Van Den Brand H, Parmentier HK, Kemp B 2004 Effects of housing system (outdoor vs cages) and age of laying hens on egg characteristics. Br Poult Sci 45:745-752.

Van Horne PLM 1996 Production and economic results of commercial flocks with white layers in aviary systems and battery cages. Br Poult Sci 37:255-261.

Vits A, Weizenburger D, Hamann H, Distl O 2005 Influence of different small group systems on production traits, egg quality and bone breaking strength of laying hens. First communication: Production traits and egg quality. Zuchtungskunde 77:303-323.

Watkins BA 1995 Biochemical and physiological aspects of polyunsaturates. Poult Avian Biol Rev 6:1-18.

Whitehead CC, Fleming RH 2000 Osteoporosis in cage layers. Poult Sci 79:1033-1041.

Yakabu A, Salako AE, Ige AO 2007 Effect of genotype and housing system on the laying performance of chickens in different seasons in semi-humid tropics. Int J Poult Sci 6: 434-439.

Yousaf M, Ahmad N 2006 Effects of housing systems on productive performance of commercial layers following induced molting by aluminium oxide supplementation. Pakistan Vet J 26:101-104.

(received: 2012. 9. 6, revised: 2012. 10. 24, accepted: 2012. 10. 30) 